\title{
Numerical Investigation of Heat Transfer Coefficient in Ribbed Rectangular Duct with Various Shaped Ribs and Different Coolants
}

\author{
Fifi N.M. Elwekeel \\ Power and Energy Engineering \\ Department \\ Harbin Engineering University \\ Harbin 150001, China,
}

\author{
Antar M.M. Abdala \\ Power and Energy Engineering \\ Department \\ Harbin Engineering University \\ Harbin 150001, China
}

\author{
Qun Zheng \\ Power and Energy Engineering \\ Department \\ Harbin Engineering University \\ Harbin 150001, China, \\ zhengqun@hrbeu.edu.cn
}

\begin{abstract}
In the present study, numerical studies are carried out to investigate the heat transfer in rectangular duct roughened by square and trapezoidal shaped ribs on one wall using different fluids. The coolant fluids such as air, steam, air/mist and steam/mist were investigated. The computational results show that the shear stress transport (SST) turbulence model is selected by comparing the predictions of different turbulence models with experimental results. The heat transfer coefficients enhance in ribbed channel at injection small amount of mist. The heat transfer coefficients of air/mist, steam/mist increase by $14 \%$ and $104 \%$ than that of air, respectively in square shaped ribs. However the heat transfer coefficient of air, air/mist, steam and steam/mist increase by $9 \%, 16 \%, 68 \%$ and $118 \%$, respectively for trapezoidal shaped ribs compared with air in square shaped ribs.
\end{abstract}

Keywords- Heat transfer; Rib roughness; mist

\section{INTRODUCTION}

Periodic ribs are frequently employed to enhance the heat transfer process in various cooling passages such as turbine blades, guide vanes and combustor walls.

Heat transfer augmentation inside cooling channels is achieved by using repeated ribs as turbulence promoters. The periodic ribs break the laminar sub-layer and create local wall turbulence due to flow separation and reattachment between the ribs, greatly enhancing the heat transfer. Several researchers have studied the heat transfer characteristics in straight channels with various shaped ribs using air as coolant flow. Chandra et al. [1], Han et al. [2], Lanjewar et al. [3], Srinath et al. [4], Salameh and Sunden [5], Tanda [6] and Wang and Sunden [7] studied experimentally the effect of ribs configuration and angled ribs on heat transfer and friction.

While by numerical predictions of the flow and heat transfer in rib-roughened passages have been conducted previously by several investigators: Kashmiri et al. [8] investigated the rib pitch effect on heat transfer.

Taslim and Liu [9], and Haasenritter et al. [10] performed

The authors would like to acknowledge the support of the China Scholarship Council (CSC) under Grant No. 2011BSZF88. both numerical and experimental analyses on roughened square channel with sharp and round profile ribs using k- $\varepsilon$ turbulence model. They found good agreement between modeling and experimental.

Chaube et al. [11] obtained a good agreement of heat transfer predicted with experimental data for roughness plate using SST k- $\omega$. Lu and Jiang [12] have performed both the numerical analysis and experimental study to investigate the heat transfer and fluid flow behavior in rectangular channel using SST k- $\omega$ and RNG k- $\varepsilon$ turbulence models. They have concluded that the SST $k-\omega$ turbulence model was more suitable for the convection heat transfer in such channels.

Wang et al. [13] examined the capabilities of different turbulence models in predicting heat transfer and flow serpentine cooling channel. They compared performance of air and steam as coolant flow. They showed the better model was SSG turbulence model and the steam heat transfer efficiency is higher than that of air.

Shui et al. [14] compared of k- $\varepsilon$ model, SST model and SSG model in prediction of heat and fluid flow of square ribbed channel. The simulation matched well with experimental results using SSG turbulence model and the steam is proper coolant than air.

Moreover, many numerical studies have been published regarding comparison analysis of air and steam as a coolant such as Albeirutty et al. [15], Najjar et al. [16] and Sanjay et al. [17]. These studies showed that the closed loop steam cooling offers the highest plant efficiency.

There have been experimental and numerical studies of tubes and flat plate cooling with air/mist including those of Sikalo et al. [18], Oisin et al. [19], Novak et al. [20], Kumari et al. [21], Shokouhmand and Ghaffari [22] and Pakhomov and Terekhov [23]. These studies concluded that the heat transfer coefficient can be increased with introduction of a fine water mist. However the experimental and numerical validation of heat transfer results of mist/steam cooling in heated horizontal tube introduced by Gou et al. [24] and Dhanasekaran and Wang 
[25] They found that the average cooling enhancement was $100 \%$ with $5 \%$ mist.

The pervious studies investigated air/mist cooling or steam $/$ mist cooling in smooth tube or flat plate. In the present work, the simulation is compared with the data of Tanda [6]. In that study, detailed heat transfer coefficients were made in a rectangular duct. The results of the heat transfer coefficient were discussed for square ribs and trapezoidal ribs using mist injection of air and steam.

\section{GEOMETRY AND COMPUTATIONAL METHODS}

Rectangular duct tested by Tanda [6] is adopted as the calculating object to verify the accuracy of calculation model and method. Fig. 1 shows the geometry and profile of the ribs for the one side ribbed duct. The ribbed side wall was denoted as the bottom surface. The other side walls were denoted as the smooth surfaces. A total of seven ribs were simulated. A multiple block structured grid is used. A grid size fell within the range of 1.2 million hexahedral elements. To accurately predict fluid behavior, the cells have been clustered towards the wall to obtain appropriate $y+$ value less than1.

The influence of turbulence models in predicting the heat transfer characteristics and flow have been tested for experimental conditions. The local heat transfer coefficient is:

$$
\mathrm{h}=\left[q /\left(T_{w}-T_{b}\right)\right]
$$

Where $q$ is heat flux $\left[\mathrm{W} / \mathrm{m}^{2} \mathrm{~K}\right], T_{w}$ and $T_{b}$ are wall temperature and bulk temperature $[\mathrm{K}]$, respectively. The local Nusselt number for the ribbed side wall is defined as

$$
N u=h D_{h} / \mathrm{k}
$$

Where $h$ is heat transfer coefficient $\left[\mathrm{W} / \mathrm{m}^{2} \mathrm{~K}\right]$ and $D_{h}$ hydraulic diameter $[\mathrm{m}]$. The ribbed side wall friction factor is defined as following:

$$
\mathrm{f}=\mathrm{D}_{\mathrm{h}} \Delta \mathrm{p} / 2 \mathrm{~L} \rho \mathrm{u}^{2}
$$

$\Delta p, L$ and $u$ are pressure loss $[\mathrm{Pa}]$ and test section length $[\mathrm{m}]$ and flow velocity $[\mathrm{m} / \mathrm{s}]$, respectively. Where, $k$ and $\rho$ are thermal conductivity $[\mathrm{W} / \mathrm{m} \mathrm{K}]$ and density $\left[\mathrm{kg} / \mathrm{m}^{3}\right]$, respectively.

Fig. 2 shows the numerical result of average Nusselt number in the ribbed wall. The friction factor at the different Re number is illustrated in Fig.3. It is clear that, the prediction by SST turbulence model is comparable with experimental data than $K \omega$ and $\omega$ RS turbulence models. So the SST turbulence model is chosen for all simulations in our study.

\section{A. Boundary conditions}

The air and steam are considered as continuous flow and mist is considered as a discrete flow in the model. The inlet mass flow rate is $0.0269 \mathrm{~kg} / \mathrm{s}$, inlet saturated temperature is $388 \mathrm{~K}$ and heat flux of $15000 \mathrm{~W} / \mathrm{m}^{2}$. The flow exit of computational domain is assumed to be a constant pressure of $1 \mathrm{~atm}$. The non slip boundary condition is assigned at all the walls, ribs and unheated walls are assigned as adiabatic wall. Mist mass fraction $6 \%$ (by mass). The boundary condition of droplets at walls is assigned as reflect [26], which means the droplets elastically rebound off once reaching the wall.
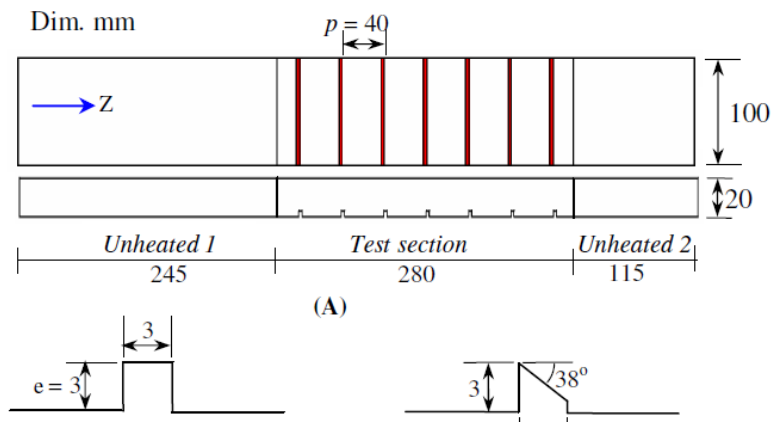

(B)

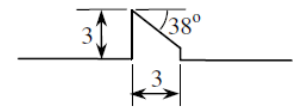

(C)

Figure 1. (a) Geometry, (b) Square ribs, (c) Trapezoidal ribs

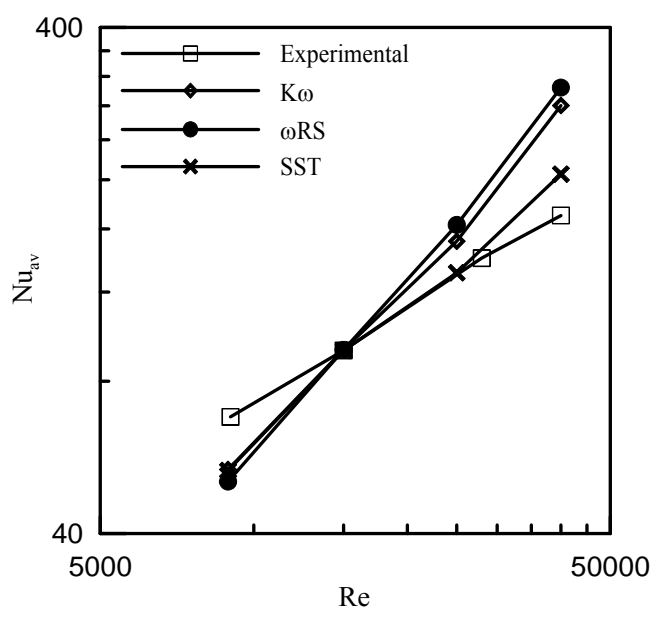

Figure 2. Effect of turbulence model on average Nu number

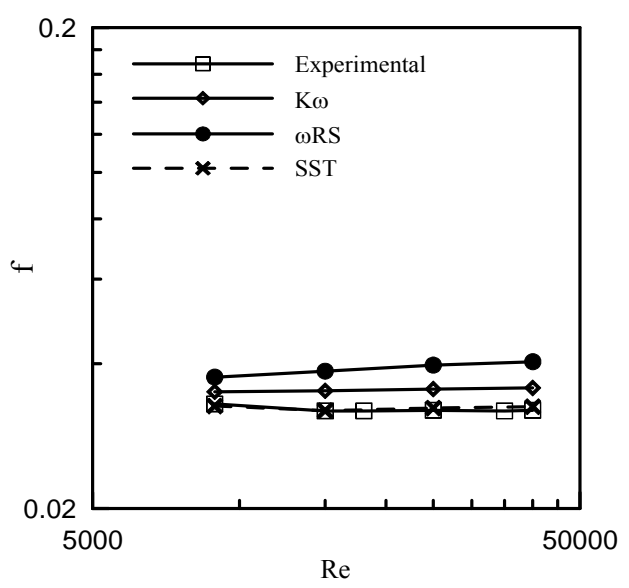

Figure 3. Variation of the friction factor with turbulence model in the ribbed duct 


\section{RESULT AND DISCUSSION}

The heat transfer coefficient in rectangular duct roughened with square ribs and trapezoidal ribs using air, air/mist, steam and steam/mist as coolants. The simulation at the same condition, the same entry static temperature and mass flow rate and outlet static pressure are employed. A uniform heat flux of $15000 \mathrm{~W} / \mathrm{m}^{2}$ is given in the wall boundary.

Fig. 4 shows the sample of flow pattern for air and air/mist for square ribs and trapezoidal ribs at the same entry conditions. Which clear that, the flow is characterized by shear layer separation and recirculation behind the ribs. Then the flow reattaches and forms recovery region at the downstream ribs. The reattachment length is proportional to the level of turbulence in the separated shear layer. The reattachment lengths of air (square ribs), air (trapezoidal ribs), air/mist (square ribs) and air/mist (trapezoidal ribs) are $4.17 \mathrm{e}, 4.22 \mathrm{e}$, $4.65 \mathrm{e}$ and $4.69 \mathrm{e}$, respectively. The air/mist (trapezoidal ribs) has the longest reattachment length. This is from the higher velocity of air/mist (trapezoidal ribs) decreases the boundary layer thickness and improves the diffusivity outer region of eddy.

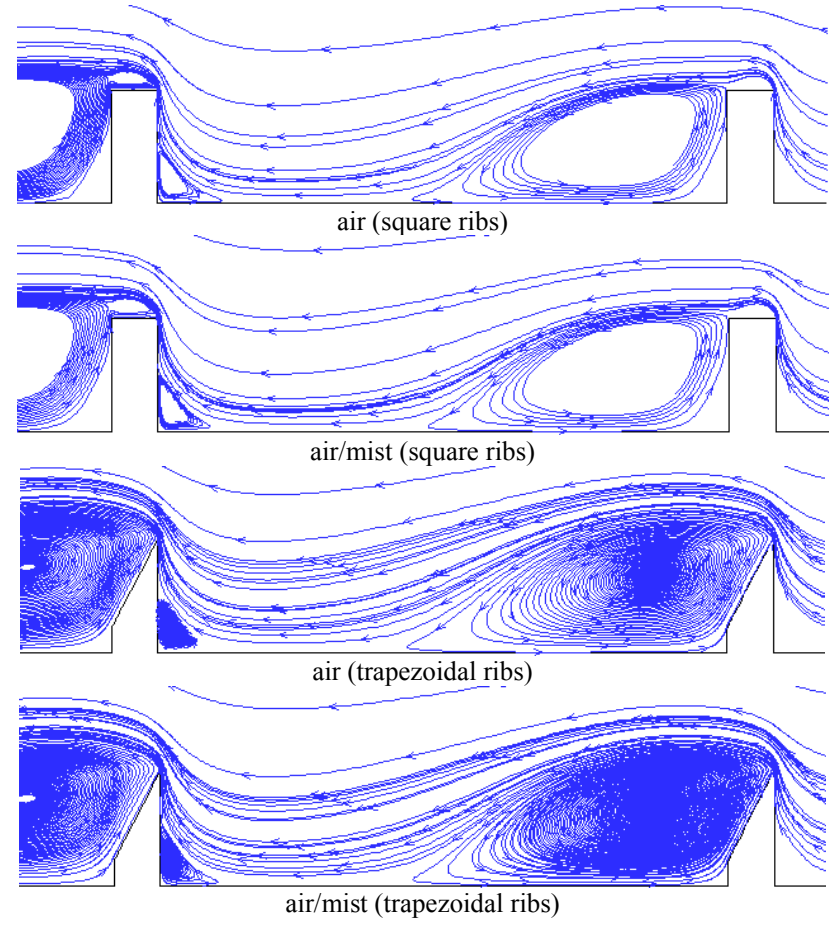

Figurer 4 Air and air/mist velocity vectors streamline diagramfor different ribs

Fig. 5 presents the air heat transfer coefficient distribution along the centerline of square ribs and trapezoidal ribs. As expected the average heat transfer coefficient of air in trapezoidal ribs case is higher than that of square ribs case. Also, it is clearly shown that the air/mist heat transfer coefficient is higher than that of air heat transfer coefficient. The average air/mist heat transfer coefficient increase by about $14 \%$ and $16 \%$ than that of air in cases, square ribs and trapezoidal ribs, respectively.

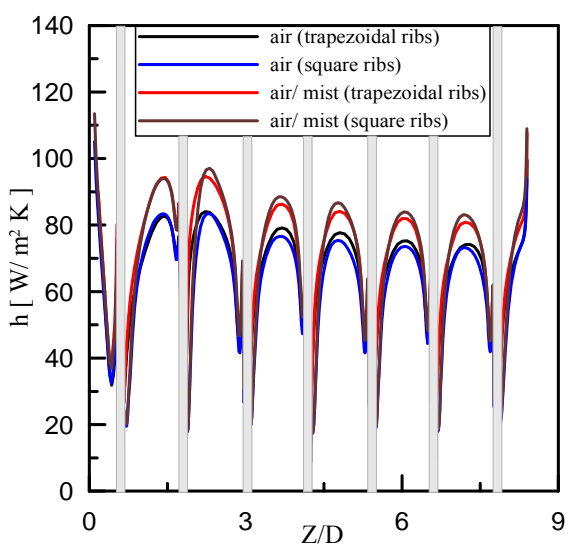

Figure 5. Local heat transfer coefficient along the centerline of air and air/mist for ribbed wall.

That is result to decrease in wall temperature (Eq.1). For average heat transfer coefficients of steam and steam/mist along the centerline are plotted in Fig. 6. The average heat transfer coefficients of steam (trapezoidal ribs) increases by about 1.09 times than that of square ribs case. Whereas the average heat transfer coefficient of steam/mist (trapezoidal ribs) increases by about $7 \%$ than that of average heat transfer coefficient of steam/mist (square ribs). That id attributed to the different separation angle when fluid approaches the different wind ward surface of the upstream rib. The average cooling enhancement for different coolant fluids over heated wall is shown in table1.

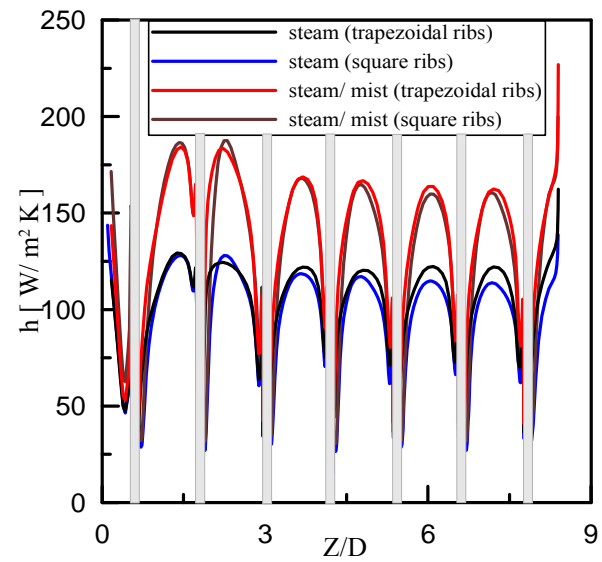

Figure 6. Local heat transfer coefficient along the centerline of steam and steam/mist for ribbed wall.

TABLE I. AVERAGE COOLING ENHANCEMENT FOR DIFFERENT COOLANT FLUIDS OVER HEATED WALL

\begin{tabular}{|c|c|c|c|}
\hline \multirow{2}{*}{ fluids } & \multicolumn{2}{|c|}{${ }^{+} h_{\text {inh }}=h / h_{\text {air }}$} & \multirow{2}{*}{$\begin{array}{c}\text { Ratio } \\
\left(\frac{h_{\text {trapezoidd }}}{h_{\text {square }}}\right)\end{array}$} \\
\cline { 2 - 3 } & $\begin{array}{c}\text { Square } \\
\text { ribs }\end{array}$ & $\begin{array}{c}\text { Trapezoidal } \\
\text { ribs }\end{array}$ & \\
\hline Air & 1 & 1.09 & 1.09 \\
\hline Air/ mist & 1.14 & 1.16 & 1.02 \\
\hline Steam & 1.54 & 1.68 & 1.09 \\
\hline Steam/ mist & 2.04 & 2.18 & 1.07 \\
\hline \multicolumn{2}{|r}{} & ${ }_{\text {hair for square ribs }}^{+}$
\end{tabular}




\section{CONCLUSIONS}

The cooling enhancement of ribbed wall using different fluids is simulated in this paper. The conclusions are as follows:

- $\quad$ SST turbulence model is performed on 90deg ribbed duct. The numerical results are compared with the experimental data from Tanda [6]. It is suggested that the SST turbulence model could provide acceptable engineering accuracy to analyze the flow and heat transfer feature in the 90 deg ribbed duct.

- $\quad$ For all coolant fluids the wall trapezoidal shaped ribs have highest heat transfer coefficient. So it is better ribs design in internal flow.

- Wall with square shaped ribs using air/mist, steam and steam/mist as coolants save $14 \%, 54 \%$ and $104 \%$, respectively compared to air to achieve the same cooling effect. Also trapezoidal shaped ribs save $9 \%, 16 \%, 68 \%$ and $118 \%$ respectively, for air, air/mist, steam and steam $/ \mathrm{mist}$ compared with air in square ribs case.

\section{REFERENCES}

[1] P. R. Chandra, C. R. Alexander and J. C. Han, "Heat transfer and friction Behaviors in Rectangular Channels with Varying Number of Ribbed Walls,” Int. J. Heat Mass Transfer, Vol. 46, pp. 481-495. 2003.

[2] J. C. Han and J. S. Park "Developing Heat Transfer in Rectangular Channels with Rib Turbulators," Int. J. Heat Mass Transfer, Vol. 31, pp. $183-195,1988$

[3] A. Lanjewar, J. L. Bhagoria and R. m. Sarviya "Heat Transfer and Friction in Solar Air Heater Duct with W- Shaped Rib Roughness on Absorber Plate," Energy, Vol. 36, pp.4531-4541, 2011.

[4] V. Srinath, Ekkad and J. C. Han "Detailed Heat Transfer Distributions in Two- pass Square Channels with Rib Turbulators," Int. J. Heat Mass Transfer, Vol. 40, pp. 2525-2537, 1997.

[5] T. Salameh and B. Sunden "An Experimental Study of Heat Transfer and Pressure Drop on the Bend Surface of a U- Duct," ASME Paper GT2010-22139, 2010.

[6] G. Tanda "Heat Transfer in Rectangular Channels with Transverse and V- Shape Broken Ribs,” Int. J. Heat Mass Transfer, Vol. 47, pp. 229-243, 2004.

[7] L. Wang and B. Sunden "Experimental Investigation of Local Heat transfer in a Square Duct with Various Shaped Ribs," Heat Mass Transfer., Vol. 43, pp. 759-766, 2007.

[8] A. Kashmiri, M. A. Cotton and Y. Addad "Numerical Simulations of Flow and heat transfer over Rib-Roughened Surfaces," 17th Annual Conference of CFD Society of Canada, Ottawa, May 3-5,2009.

[9] M. E. Taslim and H. Liu " A Combined Numerical and Experimental Study of Heat Transfer in Roughened Square Channel with 45o Ribs," Int. J. Rotating Mach., Vol.1, pp. 60-66, 2005

[10] A. Haasenritter, M. Amro and B. Weigand "an Experimental and Numerical Study of the Transfer Performance of Sharp- Edged and
Rounded Ribs in Square Ducts," The 9th International Symposium on Transport Phenomena and Dynamics of Rotating Machinery, Honolulu, Hawaii, February 10-14, 2002.

[11] A. Chaube, P. K. Sahoo and S. C. Solanki "Analysis of Heat Transfer Augmentation and Flow Characteristics due to Rib Roughness over Absorber Plate of a Solar Air Heater," Renew Energ., Vol. 31, pp. 317 331, 2006.

[12] B. Lu and P. X. Jiang "Experimental and Numerical Investigation of Convection Heat Transfer in a Rectangular Channel with Angled Ribs," Exp. Therm. Fluid Sci., Vol. 30, pp. 513-521,2006.

[13] X. Wang, W. Wang, L. Chou, , Y. Han, L. Xu and L. Shui "Flow and Heat Transfer of Air and Steam in Internal Cooling Passages of Turbine Blade," ASME Paper GT2010-22180, 2010.

[14] L. Shui, J. Gao, L. Xu and X. Wang "Numerical Investigation of Heat Transfer and Flow Characteristics in a Steam- Cooled Square ribbed Duct," ASME paper GT2010-22407, 2010.

[15] M. H. Albeirutty, A. S. Algahamdi and Y. Najjar "Heat transfer analysis for a Multistage Gas Turbine using Different Blade Cooling Schemes," Appl. Therm. Eng., Vol. 24, pp. 563-577, 2004.

[16] Y. S. H. Najjar, A. S. Alghamdi and M. H. Al-Beirutty "Comparative Performance of Combined Gas Turbine Systems under Three Different Blade Cooling Schemes," Appl. Therm. Eng., Vol. 24, pp. 1919-1934, 2004.

[17] Sanjay, O. Singh and B. N. Prasad "Comparative Performance Analysis of Cogeneration Gas Turbine Cycle for Different Blade Cooling Means," Int. J. Therm. Sci., Vol. 48, pp. 1432-1440, 2009.

[18] N. Kumari, V. Bahadur, M. Hodes, T. Salamon, and P. Kolodner "Analysis of Evaporation Mist Flow for Enhanced Convective Heat Transfer,” Int. J. Heat Mass Transfer, Vol. 53, pp. 3346-3356, 2010.

[19] N. Novak, D. L. Sadowski, K. G. Schoonover, S. I. Abdel-Khalik, and S. m. Ghiaasiaan "Heat Transfer in Two-Component Internal Mist Cooling, Part I. Experimental Investigation,” Nucl. Eng. Des., Vol. 238, pp. 23412350, 2008

[20] F. P. Oisin, Lyons, Tim, Persoons, Gerard, Byrne, B. Darina, and Murray "Water Mist/ Air Jet Cooling of a Heated Plate with Variable Droplet Size," ThETA 2, Cairo, Egypt, Dec. 17-20th, 2008.

[21] M. A. Pakhomov and V. I. Terekhov "Enhancement of Turbulent Heat Transfer During Interaction of an Impinging Axisymmetric Mist Jet with A Target,” J. Appl. Mech. Tech. Phys., Vol. 52, pp. 96-106, 2011.

[22] S. Sikalo, N. Delalic, and E. N. Ganic "Hydrodynamics and Heat Transfer Investigation of Air- Water Dispersed Flow," Exp. Therm Fluid Sci., Vol. 25, pp. 511-521, 2002.

[23] H. Shokouhmand and S. Ghaffari "Thermal Analysis of Cooling Process of a High- Temperature Vertical Hollow Cylinder using a Water- Air Spray," World Congress on Engineering, London, UK, June 30- July 2 , 2010.

[24] T. Guo, T. Wang and J. L.Gaddis "Mist/Steam Cooling in Heated Horizontal Tube- Part 2: Results and Modeling," ASME J. Turbomachinary, Vol.122, pp. 366-374, 2000.

[25] T. S. Dhanasekaran and T. Wang "Validation of Mist/ Steam Cooling CFD Model in a Horizontal Tube," ASME paper HT2008-56280, Summer Heat Transfer Conference, Jacksonville, Florida, August 10-14, 2008 .

[26] X. Li and T. Wang "Simulation of Film Cooling Enhancement with Mist Injection," ASME paper GT2005-69100, 2005. 